\section{Deoxygenation and Borylation of Ketones via Rhodium Catalysis}

Category

Metals in Synthesis

\section{Key words}

rhodium catalysis

deoxygenation

vinyl boronates
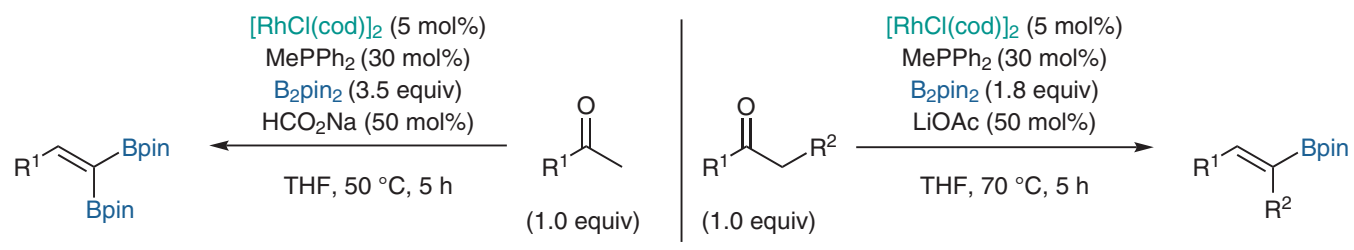

$\mathrm{R}^{1}=\left(\right.$ Het)Ar, Alk; $\mathrm{R}^{2}=\mathrm{H}$, Alk

up to $84 \%$ yield $>30$ examples

up to $86 \%$ yield $>30$ examples

Selected examples: vinylboronates
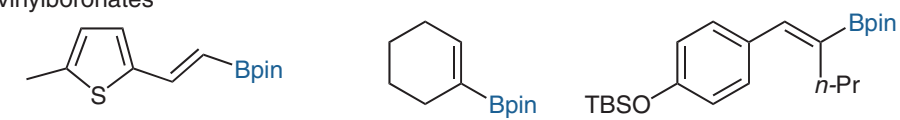
$43 \%$ yield $74 \%$ yield

1,1-diborylalkenes<smiles>BrCC(Br)=Cc1ccccc1</smiles>

$86 \%$ yield

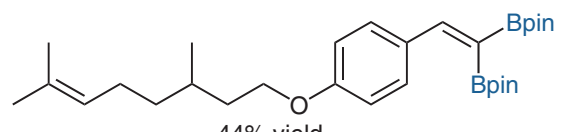
$44 \%$ yield<smiles>COc1cc(/C=C/P)cc(OC)c1</smiles>

Proposed mechanism:
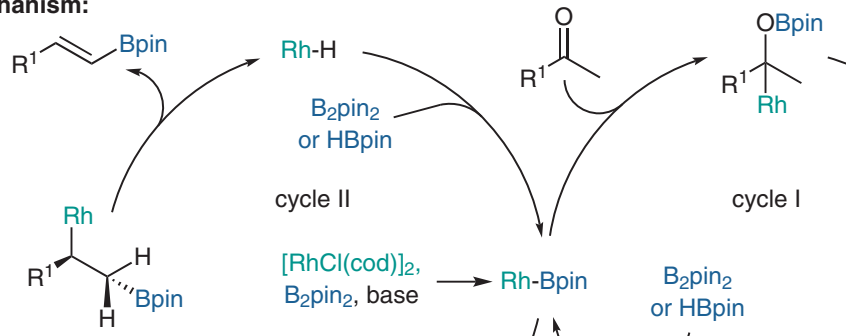

$[\mathrm{RhCl}(\mathrm{cod})]_{2}$,

$\mathrm{B}_{2} \mathrm{pin}_{2}$, base
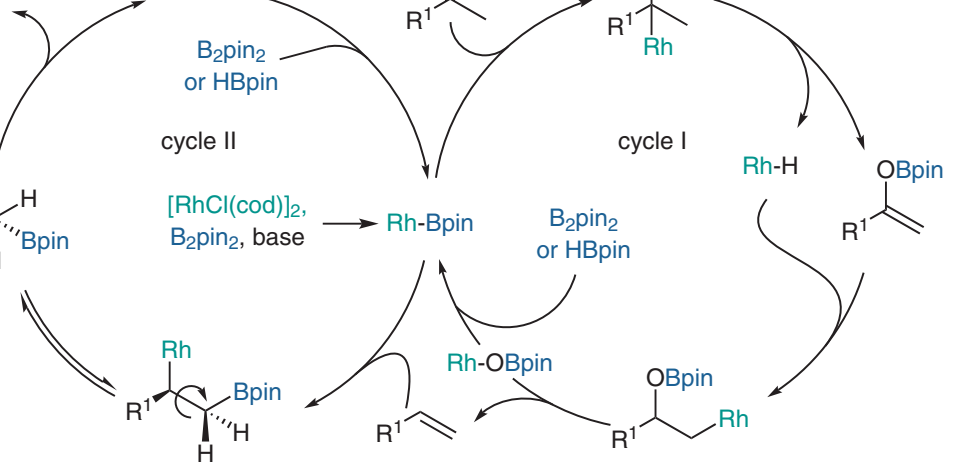

Significance: The authors report a rhodium-catalyzed deoxygenation reaction using $\mathrm{B}_{2} \mathrm{pin}_{2}$. The resulting alkenes may subsequently be mono- or diborylated. The olefins, vinylboronates or 1,1-diborylalkenes, are obtained stereoselectively in high yields under mild reaction conditions. A broad range of functional groups are tolerated under these conditions. Olefins were obtained using DPEPhos (7.5 mol\%), $\mathrm{B}_{2} \mathrm{Pin}_{2}$ (1.1 equiv), and $\mathrm{K}_{2} \mathrm{CO}_{3}$ as a base in hexane. A broad variety of synthetic applications of the boron species are reported, including gram-scale transformations and the synthesis of biologically active compounds.
Comment: A mechanism based on experimental as well as computational studies is proposed. Control experiments showed that alkenes are intermediates of the deoxygenative borylation. Furthermore, subjecting vinylboronates to the standard conditions for the diborylation indicated that the 1,1-diborylalkenes are formed via a vinylboronate intermediate. According to DFT calculations, the 1,2-addition of the Rh-Bpin to the carbonyl compound is the rate-limiting step of the reaction. $\sigma$-Bond metathesis between $\mathrm{B}_{2} \mathrm{Pin}_{2}$ and Rh-OBpin regenerates the $\mathrm{Rh}$-Bpin. 